\title{
APPLICATION OF THERMO-CHEMICAL TECHNOLOGIES FOR CONVERSION OF ASSOCIATED GAS IN DIESEL-GAS TURBINE INSTALLATIONS FOR OIL AND GAS FLOATING UNITS
}

\author{
Oleksandr Cherednichenko \\ Serhiy Serbin \\ Admiral Makarov National University of Shipbuilding, Ukraine \\ Marek Dzida \\ Gdańsk University of Technology, Poland
}

\begin{abstract}
The paper considers the issue of thermo-chemical recovery of engine's waste heat and its further use for steam conversion of the associated gas for oil and gas floating units. The characteristics of the associated gas are presented, and problems of its application in dual-fuel medium-speed internal combustion engines are discussed. Various variants of combined diesel-gas turbine power plant with thermo-chemical heat recovery are analyzed. The heat of the gas turbine engine exhaust gas is utilized in a thermo-chemical reactor and a steam generator. The engines operate on synthesis gas, which is obtained as a result of steam conversion of the associated gas. Criteria for evaluating the effectiveness of the developed schemes are proposed. The results of mathematical modeling of processes in a $14.1 \mathrm{MW}$ diesel-gas turbine power plant with waste heat recovery are presented. The effect of the steam/associated gas ratio on the efficiency criteria is analyzed. The obtained results indicate relatively high effectiveness of the scheme with separate high and low pressure thermo-chemical reactors for producing fuel gas for both gas turbine and internal combustion engines. The calculated efficiency of such a power plant for considered input parameters is $45.6 \%$.
\end{abstract}

Keywords: thermo-chemical heat recovery, gas turbine engine, diesel engine, associated gas, steam reforming, efficiency, methane number

\section{INTRODUCTION}

The development of the global economy generates growing demand for oil and gas. At the same time, there is a decrease in the number of promising mainland deposits. The vector of fossil hydrocarbon extraction is steadily shifting to the area of the continental shelf. Over $37 \%$ of the world oil production and $28 \%$ of gas production come from fields located on the shelf [1]. Essentially, these deposits are located in the Middle East, Brazil, the Gulf of Mexico, the North and Caspian seas, and on the Arctic shelf. The recently discovered offshore oil and gas deposits are about 10 times larger than newly discovered land deposits. The development of the continental shelf deposits creates the basis for providing the world economy with hydrocarbon raw materials for the long perspective.

Oil and gas floating units are located at significant distances from the coast. At the same time, various technologies and technical means are successfully applied and developed for various climatic conditions. An increasing number of oil and gas production facilities are related to deep water $(0.4 \ldots 1.5$ $\mathrm{km}$ ) and ultra deep water (over $1.5 \mathrm{~km}$ ). The process of oil and gas extraction from the sea shelf is energy intensive, and with the increase of extraction depth the energy costs also grow higher. At the same time, the emissions of greenhouse gases produced by power plants increase as well.

The need to solve the problems of improving fuel efficiency and reducing harmful emissions during power equipment 
operation is a paradigm for designing power plants for marine vessels and ocean engineering objects. All this requires defining new promising ways to improve the efficiency of oil and gas production power plants.

\section{IDENTIFICATION OF THE INVESTIGATION OBJECT}

Low-speed two-stroke diesel engines (2SDE) are most widespread in the ship power industry. 2SDE have high efficiency and can work on cheap heavy grades of fuel oil. The efficiency of such power plants can be improved due to the recovery of energy resources [2]. Large weight and size indicators of such engines do not allow their use in power plants of oil and gas floating units.

The main thermal engines used in power installations of oil and gas floating units are gas turbine engine (GTE) and medium speed four-stroke diesel engine (4SDE). Despite the fact that the efficiency of internal combustion engines is higher, the advantage is given to GTEs, as they better satisfy the requirements of ensuring high power with small weight and size parameters.

A large number of publications are devoted to solving the problem of increasing the efficiency of gas-turbine engines for oil and gas production facilities. One of the ways to increase this efficiency can be humidification of the air entering the GTE compressor [3]. The most widespread way to increase gas turbine unit efficiency is to use the heat of the waste gas in the combined gas-steam turbine cycle. Combined-cycle power plants of this type have been installed on three Norwegian gas fields [4]. It was revealed that large mass and dimensions of the steam-turbine circuit equipment [5] restrain the use of such technologies at oil and gas production facilities.

Fuel characteristics largely determine the performance indicators of thermal engines, including GTE [6]. 4SDE and GTE are dual-fuel engines, adapted to operate on gaseous and liquid fuels. The associated gas, separated from crude oil, can also be used as a fuel. The composition of the associated gas varies and it can contain a lot of heavier hydrocarbons [7-11].

The use of such a fuel in an internal combustion engine can cause problems associated with significant influence of fuel composition on the engine's working process. The methane number is the measure of resistance of the gas fuel to knock. Leading manufacturers of marine internal combustion engines restrict the lower limit of the fuel methane number (MN). For example, for Wartsila dual-fuel engines, fuels with methane number $\mathrm{WMN}<46.8$ are not recommended for use. Moreover, the molar methane content should not be less than $70 \%$, and $\mathrm{H}_{2}$ should not be more than $30 \%$ [12].

The authors have carried out calculations of the methane number for associated gases with different compositions [7-11]. The calculations were carried out using the Wärtsilä Methane number calculator, as well as the method of the Gas Research Institute [13]. The results of the MN and Low Calorific Value (LCV) calculations are presented in Table 1.
Tab. 1. Parameters of associated gas

\begin{tabular}{|l|c|c|c|c|c|}
\hline Parameters & \multicolumn{5}{|c|}{ Value } \\
\hline Designation of associated gas & A1 & A2 & A3 & A4 & A5 \\
\hline \multicolumn{5}{|c|}{ Chemical compound (\%, mol) } \\
\hline Reference source & {$[7]$} & {$[8]$} & {$[9]$} & {$[10]$} & {$[11]$} \\
\hline Methane $\left(\mathrm{CH}_{4}\right)$ & 68.00 & 62.77 & 73.7 & 64.48 & 67.32 \\
\hline Ethane $\left(\mathrm{C}_{3} \mathrm{H}_{8}\right)$ & 15.00 & 15.07 & 6.70 & 11.98 & 17.66 \\
\hline Propane $\left(\mathrm{C}_{2} \mathrm{H}_{6}\right)$ & 9.00 & 6.64 & 6.10 & 8.75 & 8.95 \\
\hline Butane $\left(\mathrm{C}_{4} \mathrm{H}_{10}\right)$ & 5.00 & 2.40 & 3.89 & 3.84 & 4.20 \\
\hline Pentane and Heaver $\left(\mathrm{C}_{5}+\right)$ & 1.00 & 1.12 & 3.70 & 2.02 & 1.87 \\
\hline Hydrogen Sulfide $\left(\mathrm{H}_{2} \mathrm{~S}\right)$ & - & 2.80 & 0.20 & 0.57 & - \\
\hline Carbon Dioxide $\left(\mathrm{CO}_{2}\right)$ & 1.00 & 9.20 & 1.34 & 0.63 & - \\
\hline Nitrogen $\left(\mathrm{N}_{2}\right)$ & 1.00 & - & 4.37 & 3.73 & - \\
\hline Water vapor $\left(\mathrm{H}_{2} \mathrm{O}\right)$ & - & - & - & 4.00 & - \\
\hline \multicolumn{7}{|c|}{ Methane $\mathrm{Number}$ Calculation } \\
\hline $\begin{array}{l}\text { Wärtsilä Methane Number } \\
\text { (WMN) }\end{array}$ & $<46.8$ & $<46.8$ & $<46.8$ & $<46.8$ & $<46.8$ \\
\hline $\begin{array}{l}\text { GRI methods: } \\
\text { Linear coefficient relation } \\
\text { (GRI LCR MN) }\end{array}$ & 27.5 & 47.3 & 42.6 & 21.5 & 26.1 \\
\hline $\begin{array}{l}\text { Hydrogen/carbon ratio relation } \\
\text { Calculation }\end{array}$ & 64.4 & 53.4 & 61.2 & 53.3 & 67.9 \\
\hline LCV, MJ/kg & 46.3 & 38.6 & 44.0 & 42.9 & 47.9 \\
\hline
\end{tabular}

To prepare the associated gas for use as fuel in an internal combustion engine, Wartsila developed the steam reforming based GasReformer Technology. According to this technology, the methane number of the fuel gas is improved by converting heavier hydrocarbons into synthesis gas and methane [14]. The patented Wärtsilä GasReformer executes the conversion of the associated gas with steam reforming on nickel catalysts $\left(\mathrm{Ni} / \mathrm{MgAl}_{2} \mathrm{O}_{4}\right)$. Since nickel catalysts are very sensitive to sulfur compounds, frequent desulfurization is envisaged. In addition, during the gas reformer operation, intense deactivation of the nickel catalyst takes place due to carbon deposition on the catalyst surface. The installation is designed to work with $4 \ldots 12 \mathrm{MW} 4$ SDE Wärtsilä engines. The claimed efficiency is $44.5 \%$.

Steam reforming of hydrocarbon fuels is accompanied by endothermic reactions of steam reforming (1) and decomposition (2) requiring external heat supply $(+\Delta \mathrm{H})$, as well as exothermic reaction $(-\Delta \mathrm{H})$ of water-gas shift (3):

$$
\begin{gathered}
\mathrm{C}_{\mathrm{n}} \mathrm{H}_{\mathrm{m}} \mathrm{O}_{1}+\mathrm{H}_{2} \mathrm{O} \rightarrow \mathrm{H}_{2}+\mathrm{CO} \\
\mathrm{C}_{\mathrm{n}} \mathrm{H}_{\mathrm{m}} \mathrm{O}_{1} \rightarrow \mathrm{CH}_{4}+\mathrm{H}_{2}+\mathrm{CO} \\
\mathrm{CO}+\mathrm{H}_{2} \mathrm{O} \leftrightarrow \mathrm{H}_{2}+\mathrm{CO}_{2}
\end{gathered}
$$

The main components of the synthesis gas that can be obtained as a result of steam reforming are $\mathrm{H}_{2}, \mathrm{CO}, \mathrm{CO}_{2}$, 
$\mathrm{CH}_{4}$, and $\mathrm{H}_{2} \mathrm{O}$. During steam reforming of hydrocarbon fuels, an increase of the process pressure results in the shift of the conversion efficiency region to a high temperature zone. At the same time, the pressure of the gaseous fuel supplied to the gas turbine engine is $1.5 \ldots 3 \mathrm{MPa}$, while to the $4 \mathrm{SDE}$, the gaseous fuel is fed at a pressure of 0.5...0.6 MPa. The conversion executed at pressures close to atmospheric can be effective at lower process temperatures, but it requires considerable power inputs to compress the obtained synthesis gas before it enters the engine.

Thermo-chemical conversion of heavy hydrocarbons into synthesis gas can be carried out using plasma-chemical methods $[15,16,17]$. The plasma-chemical technologies are used to intensify the process of burning the synthesis gas of various composition, including low $\operatorname{LCV}[18,19,20]$.

One of the promising ways to improve the power plant efficiency is the use of engine's exhaust energy to support endothermic reactions of steam reforming of hydrocarbon fuels with different compositions.

The previously conducted researches have shown that the thermal potential of the secondary energy resources in the internal combustion engine does not provide opportunities for efficient conversion of associated gas components. On the other hand, the temperature range of the exhaust gases in modern commercial GTEs enables efficient conversion of heavy hydrocarbons being part of the associated gas.

The diagram of the combined diesel-gas turbine power plant with thermo-chemical heat recovery (COGED+TCR) is considered in [21]. This diagram presents steam reforming of natural gas or cargo vapor products on LNG gas carriers. The heat source for conversion is the heat of GTE off-gases.

The COGED+TCR installation can be applied on oil and gas floating units which utilize the associated gas with different composition as a fuel.

\section{CHARACTERISTICS OF POWER PLANTS WITH CONVERSION OF ASSOCIATED GAS FOR OIL AND GAS FLOATING UNITS}

Figure 1 shows two variants of the combined COGED+TCR installation. The plant consists of a gas turbine unit based on a simple cycle gas turbine engine and two dual-fuel 4SDEs. All engines run on products of associated gas reforming. The heat of the GTE exhaust gas is utilized in a thermo-chemical reactor and a steam generator.

In the diagram with single reactor (Fig. 1A), the conversion of the associated gas is carried out at the pressure corresponding to the feed pressure in the internal combustion engine $(0.6 \mathrm{MPa})$. This moderate process pressure implies a shift in the effective conversion range to a region of relatively low temperatures corresponding to the GTE exhaust gas temperature. The synthesis gas obtained in the reactor is passed to the dehydrator. The drained synthesis gas has a significantly lower content of non-combustible components, which significantly simplifies the processes of mixture formation and combustion. The disadvantage with respect to gas turbine engines is that dehydration of the synthesis gas results in the loss of thermal potential of the steamand-gas mixture. Further, the dried synthesis gas is divided into two streams. The first stream is passed to the internal combustion engine, while the second stream is compressed in the compressor to the feed pressure in the GTE $(1.5 \mathrm{MPa})$. The water obtained in the dehydration process returns to the cycle.

In the second case (Fig. 1B), two reactors are provided with high pressure of $1.5 \mathrm{MPa}$ and low pressure of $0.6 \mathrm{MPa}$. From the high-pressure reactor, which has a sufficiently high temperature, the steam-and-gas mixture flows into the combustion chamber, like in the STIG cycle. After leaving the low-pressure reactor, the synthesis gas undergoes the dehydration process and is further fed to the internal combustion engine.
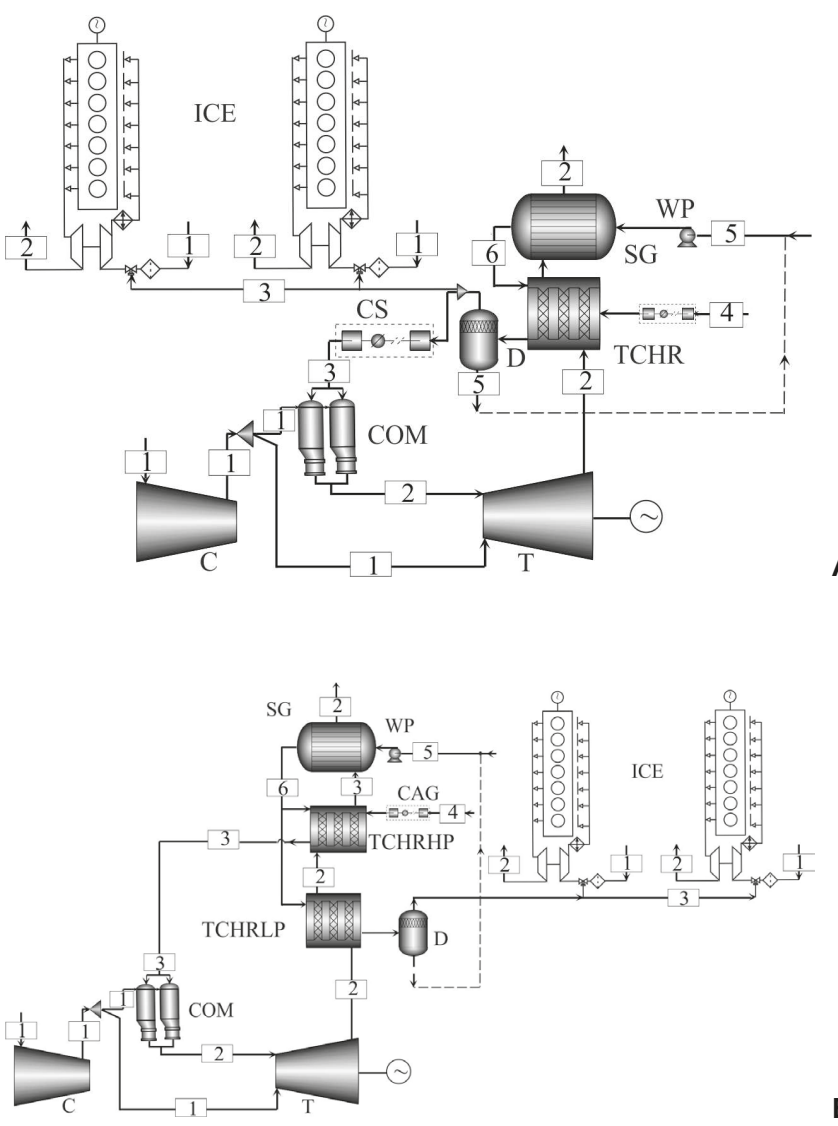

Fig. 1. Simplified calculation schemes of a COGED+TCR plant. A - scheme with single unit reactor, $\boldsymbol{B}$-scheme with double unit reactor. Designations: 1 - air, 2 - gas, 3 - syngas, 4 - associated gas, 5 - water (steam), $C$ - compressor; $C A G$ - associated gas compressor; COM - combustor; CS - syngas compressor; D - degasifier; SG - steam generator; $T$ - gas turbine; TCHR, TCHRLP, TCHRHP - thermo-chemical reactor; WP - water pump

The applicability range of the developed COGED+TCR diagrams was evaluated using mathematical modelling of processes. In this modeling, the power plant was structurally considered as a system of three functionally interconnected subsystems:

- energy subsystem, in which the chemical energy of the fuel is converted into mechanical and thermal energy; 
- recovery subsystem, designed to convert the waste heat of the energy subsystem into mechanical and thermal forms of energy;

- associated gas conversion subsystem.

The range of applicability of the proposed diagrams can be comprehensively evaluated based on the efficiency of use of the chemical energy of the associated gas and the efficiency of the thermo-chemical conversion of heavy hydrocarbons being part of the associated gas.

As the criterion of the fuel energy efficiency, the efficiency of the installation was provided:

$$
\eta=\frac{N_{c o m b i}}{m_{\Sigma f} \cdot L C V}
$$

where $N_{c o m b i}$ is the power output of the combined plant, and $m_{\Sigma f}$ is the fuel mass flux.

$$
\begin{gathered}
N_{\text {combi }}=i \cdot N_{G T E}+j \cdot N_{4 S D E} \\
m_{\Sigma f}=m_{\Sigma G T E}+m_{\Sigma 4 \mathrm{SDE}}
\end{gathered}
$$

In Eqs. 5 and 6, $i$ and $j$ are the numbers of gas turbine and diesel engines, $N_{G T E}, N_{4 S D E}$ are the power outputs of the gas turbine and diesel engines, and $m_{\Sigma \mathrm{GTE}}, m_{\Sigma 4 \mathrm{SDE}}$ are the fuel mass fluxes of the gas turbine and diesel engines, respectively.

The plant power and the associated gas LCV are considered as constants. In this case, the efficiency criterion is the function of change of fuel consumption rate

$$
\eta=f\left(\Delta m_{\Sigma f}\right)
$$

where $\Delta m_{\Sigma f}$ is the change of consumption rate of the associated gas fed to the gas turbine engine, or to the internal combustion engine.

As criteria of the efficiency of thermo-chemical conversion of heavy hydrocarbons contained in the associated gas, two parameters were taken:

- the rate of conversion of the corresponding hydrocarbon (ethane, propane, butane, pentane);

- the methane number, defined as WMN and GRI Linear Coefficient Relation MN.

The conversion rate is defined as

$$
\xi=\frac{\left(q_{i n}^{m}-q_{o u t}^{m}\right)}{q_{i n}^{m}}
$$

where $q_{i n}^{m}$ is the mole fraction of the corresponding hydrocarbon in the associated gas, and $q_{o u t}^{m}$ is the mole fraction of the corresponding hydrocarbon in the fuel gas fed to the internal combustion engine.

The methane number defined as WMN and GRI LCR MN was used as the criterion of energy efficiency of the thermo-chemical conversion of heavy hydrocarbons contained in the fuel gas fed to the internal combustion engine.

The WMN was determined using the on-line Wärtsilä Methane number calculator program. To calculate the GRI LCR MN, the following dependency was considered [13]:

$$
\begin{gathered}
\text { GRI LCR MN }= \\
=1.445 \cdot\left(137.78 \cdot \mathrm{x}_{1}+29.948 \cdot \mathrm{x}_{2}-18.193 \cdot \mathrm{x}_{3}-\right. \\
\left.-167.062 \cdot \mathrm{x}_{4}+181.233 \cdot \mathrm{x}_{5}+26.994 \cdot \mathrm{x}_{6}\right)-103.42
\end{gathered}
$$

In Eq. 9, $\mathrm{x}$ represents the mole fraction of an individual component: $\mathrm{CH}_{4}=\mathrm{x}_{1} ; \mathrm{C}_{2} \mathrm{H}_{4}=\mathrm{x}_{2} ; \mathrm{C}_{3} \mathrm{H}_{8}=\mathrm{x}_{3} ; \mathrm{C}_{4} \mathrm{H}_{10}=\mathrm{x}_{4}$; $\mathrm{CO}_{2}=\mathrm{x}_{5} ; \mathrm{N}_{2}=\mathrm{x}_{6}$.

The basis for the mathematical model of the gas turbine block is the extended GTE calculation which takes into consideration total pressure losses. The combustion chamber model is based on combined chemical and phase equilibrium, while to determine the composition of the components, the Gibbs free energy for reaction products is minimized. Note that the obtained synthesis gas has a low calorific value and high content of non-combustible impurities, therefore it is advisable to use a plasma-chemical intensification system to initiate the burning process in the gas turbine combustion chamber $[22,23]$.

The rate of the waste gas heat required for fuel conversion was determined from the thermo-chemical reactor heat balance.

The modeling of the power plants was based on the gas turbine engine UGT 2500 and two medium-speed 4SDE engines Wärtsilä 6L50DF. The total plant power was 14.1 MW.

The simulation of the GTE processes was carried out for the parameters of the basic turbo-compressor unit, with the following restrictions:

- fixed GTE power (2.7 MW);

- fixed gas turbine inlet temperature $\left(T_{3}=1223 \mathrm{~K}\right)$;

- environmental parameters according to ISO 3046-1:2002.

With regard to the 4SDE engine Wärtsilä 6L50DF with fixed power (5.7 MW) and total energy consumption at $100 \%$ load $(7.41 \mathrm{MJ} / \mathrm{kWh})$, the change in fuel consumption in terms of LCV associated gas supplied to the power plant was determined.

Mathematical modelling of the processes in the plant has revealed that the diagram shown in Fig. 1A has low fuel energy efficiency. The energy consumed for compressing the dried synthesis gas to the GTE feed pressure is larger than the increase in energy efficiency due to steam reforming of the associated gas. As a result, the efficiency of the installation shown in the diagram in Fig. 1A is comparable to or lower than the baseline plant efficiency without TCR. The efficiency calculation of thermo-chemical conversion parameters showed complete conversion of heavy hydrocarbons (Fig. 2). 


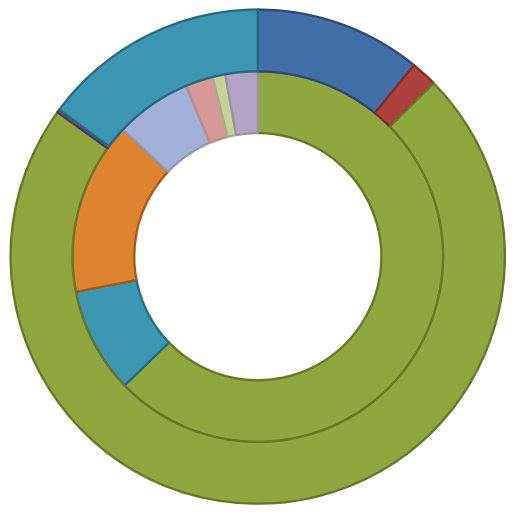

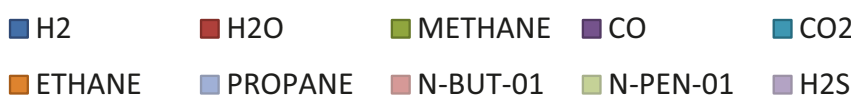

Fig. 2. Comparing chemical compounds $(\%, \mathrm{~mol})$ of the associated gas (inner ring) with the resulting synthesis gas conversion products (outer ring)

The results of modelling of the processes in the power plant shown in Fig. 1B have demonstrated good effectiveness of this scheme. Due to the steam reforming of the associated gas and the use of the potential of the steam-gas mixture, the mass flow rate of the associated gas used as GTE fuel decreased by $19 . . .20 \%$ (Fig. 3), which resulted in the increase of the gas turbine unit efficiency by $6.8 \%$.

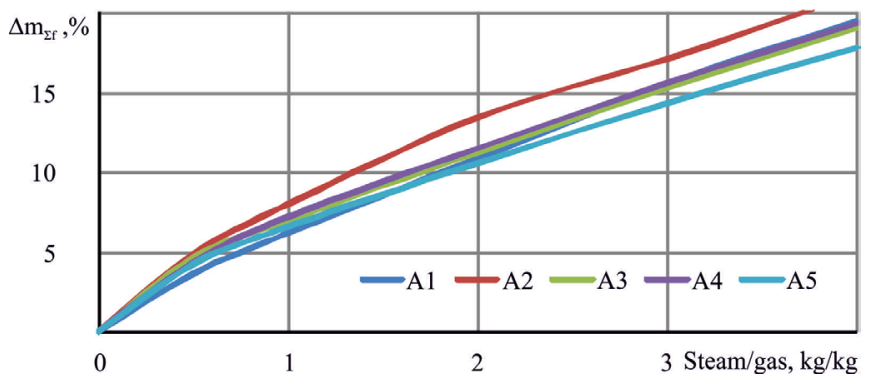

Fig. 3. Decrease in mass flow rates of associated gases with different compositions depending on the water/gas ratio (mass)

As a result of the use of thermo-chemical heat recovery of the waste gas, the calculated efficiency of the COGED+TCR unit (45.6\%) increased by $3 \%$ compared with the basic COGED power plant. This result is comparable to the declared Wärtsilä GasReformer data.

The performed simulation made it possible to determine the composition of the synthesis gas obtained as a result of conversion of associated gases with different compositions (Table 2).

Tab. 2. Parameters of fuel gases fed to internal combustion engines

\begin{tabular}{|l|c|c|c|c|c|c|}
\hline Parameter & \multicolumn{5}{|c|}{ Value } \\
\hline $\begin{array}{l}\text { Designation of base associated gas } \\
\text { (Tab. } 1)\end{array}$ & A1 & A2 & A3 & A4 & A5 \\
\hline $\begin{array}{l}\text { Chemical compound of fuel gas fed to internal combustion engine, } \\
(\%, \text { mol })\end{array}$ & 12.7 & 10.7 & 11.7 & 11.4 & 12.9 \\
\hline Hydrogen $\left(\mathrm{H}_{2}\right)$ & 1.7 & 1.7 & 1.7 & 1.7 & 1.7 \\
\hline Water vapor $\left(\mathrm{H}_{2} \mathrm{O}\right)$ & 74.0 & 71.3 & 73.4 & 73.7 & 74.6 \\
\hline Methane $\left(\mathrm{CH}_{4}\right)$ &
\end{tabular}

\begin{tabular}{|l|c|c|c|c|c|}
\hline Parameter & \multicolumn{5}{|c|}{ Value } \\
\hline Carbon Oxide $(\mathrm{CO})$ & 0.2 & 0.2 & 0.1 & 0.2 & 0.1 \\
\hline Carbon Dioxide $\left(\mathrm{CO}_{2}\right)$ & 10.6 & 14.6 & 10.3 & 10.4 & 10.7 \\
\hline Nitrogen $\left(\mathrm{N}_{2}\right)$ & 0.8 & 1.5 & 2.8 & 2.6 & 78 \\
\hline $\begin{array}{l}\text { Calculated Wärtsilä methane } \\
\text { number }\end{array}$ & 78 & 82 & 77 & 78 & 87 \\
\hline $\begin{array}{l}\text { Calculated GRI LCR methane } \\
\text { number, Eq. (6) }\end{array}$ & 78 & 84 & 76.7 & 77.6 & 79.3 \\
\hline LCV, MJ/kg & 35.7 & 28.1 & 30.5 & 34.7 & 36.2 \\
\hline
\end{tabular}

The efficiency calculations of the thermo-chemical conversion of heavy hydrocarbons in associated gases with different compositions have shown that the obtained values correspond to the Wärtsilä requirements for the methane number and chemical composition of the fuel gas.

The main characteristics of the COGED+TCR unit with separate high and low pressure thermo-chemical reactors are given in Table 3.

Tab. 3. Design product specification of COGED+TCR unit with separate high and low pressure thermo-chemical reactors (total power $14.1 \mathrm{MW}$ )

\begin{tabular}{|l|c|c|}
\hline Parameter & Unit & Value \\
\hline $\begin{array}{l}\text { Pressure: } \\
\text { high pressure reactor } \\
\text { low pressure reactor }\end{array}$ & $\mathrm{MPa}$ & 1,4 \\
\hline $\begin{array}{l}\text { Temperature of synthesis gas: } \\
\text { high pressure reactor - in/out } \\
\text { low pressure reactor - in/out }\end{array}$ & $\mathrm{K}$ & $\begin{array}{c}714 / 680 \\
675-660\end{array}$ \\
\hline $\begin{array}{l}\text { Specific mass flow rate per 1 MW shaft power: } \\
\text { feed gas mass flow rate } \\
\text { total steam demand: } \\
\quad \begin{array}{l}\text { of which recycled boiler water } \\
\text { of which fresh water }\end{array}\end{array}$ & $\mathrm{kg} /(\mathrm{MW} \cdot \mathrm{h})$ & $\begin{array}{c}300-350 \\
120-140 \\
180-210\end{array}$ \\
\hline $\begin{array}{l}\text { Energy consumption for compressors and } \\
\text { pumps }\end{array}$ & $\mathrm{kW}$ & $25-30$ \\
\hline
\end{tabular}

\section{FINAL CONCLUSIONS}

The use of thermo-chemical conversion to recover the heat from the engine's exhaust gas and further utilization of this heat for steam reforming of heavy hydrocarbons expand the possibilities of using the associated gas as fuel in power plants for oil and gas floating units.

It is rational to carry out thermo-chemical conversion of the associated gas in a COGED+TCR unit with separate high and low pressure thermo-chemical reactors to produce fuel gas for both gas turbine engines and internal combustion engines.

COGED+TCR power plants make it possible to combine attractive advantages of low weight and size of a marine gas turbine engine without reducing the energy efficiency.

In this work, only the thermodynamic analysis of the COGED+TCR power plant is presented. An additional feasibility study is needed to fully assess the application range of such an installation for oil and gas floating units. 


\section{BIBLIOGRAPHY}

1. WOR 3 (2014): Marine Resources - Opportunities and Risks. Retrieved from https://worldoceanreview.com/en/wor-3/

2. Olszewski W., Dzida M. (2018): Selected Combined Power Systems Consisted of Self-Ignition Engine and Steam Turbine. Polish Maritime Research, No.1, Vol. 25, 198-203.

3. Domachowski Z., Dzida M. (2019): Applicability of Inlet Air Fogging to Marine Gas Turbine. Polish Maritime Research, No.1, Vol. 26, 15-19.

4. Mazzetti M. J., Nekså P., Walnum H. T., Hemmingsen A. T. (2014): Energy-Efficient Technologies for Reduction of Offshore $\mathrm{CO}_{2}$ Emissions. Oil and Gas Facilities, February 2014, 8996.

5. Szymaniak M. (2018): Steam Turbine Stage Modernisation in Front of the Extraction Point. Polish Maritime Research, No.2, Vol. 25, 116-122.

6. Sarnecki J., Białecki T., Gawron B., Głąb J., Kamiński J., Kulczycki A., Romanyk K. (2019) Thermal Degradation Process of Semi-Synthetic Fuels for Gas Turbine Engines in Non-Aeronautical Applications. Polish Maritime Research, No.1, Vol. 26, 65-71.

7. Michael Farry (1998) Ethane from associated gas still the most economical. Retrieved from https://www.ogj. com/articles/print/volume-96/issue-23/in-this-issue/gasprocessing/ethane-from-associated-gas-still-the-mosteconomical.html, Accessed 20 May 2019.

8. Al-Saleh M.A., Duffuaa S.O.,. Al-Marhoun M.A, Al-Zayer J.A. (1991): Impact of crude oil production on the petrochemical industry in Saudi Arabia. Retrieved from https://www.researchgate.net/publication/256569784_ Impact_of_crude_oil_production_on_the_ petrochemical_industry_in_Saudi_Arabia/ figures.

9. Nguyen T., Elmegaard B., Pierobon L., Haglind F., Breuhaus P. (2012): Modelling and analysis of offshore energy systems on North Sea oil and gas platforms. 53-rd International Conference of Scandinavian Simulation Society, SIMS 2012. Retrieved from https:// www.researchgate.net/publication/263973093_ Modelling_and_analysis_of_offshore_energy_ systems_on_North_Sea_oil_and_gas_platforms/ figures? $10=1$.

10. Foss M. M. (2004): Interstate natural gas quality specifications \& interchangeability. Center for Energy Economics. Retrieved from http://www.beg.utexas.edu/files/ energyecon/global-gas-and-lng/CEE_Interstate_Natural_ Gas_Quality_Specifications_and_Interchangeability.pdf.
11. Oil \& Gas Industry Overview (2019): Crude Oil and Natural Gas: From Source to Final Products. Retrieved from https://www.ihrdc.com/els/po-demo/module01/ mod_001_02.htm.

12. WÄRTSILÄ (2019): Wärtsilä Methane number calculator. Retrieved from https://www.wartsila.com/products/ marine-oil-gas/gas-solutions/methane-number-calculator.

13. ISO/TR 22302:2014 (2014): Natural gas. Calculation of methane number.

14. WÄRTSILÄ (2015): Wärtsilä GasReformer. Retrieved from https://www.offshore-europe.co.uk/_novadocuments/31 $687 ? \mathrm{v}=635089663131000000$.

15. Gatsenko NA., Serbin SI. (1995). Arc plasmatrons for burning fuel in industrial installations, Glass and Ceramics, vol. 51 (11-12), 383-386

16. Matveev I. B., Tropina A. A., Serbin S. I., Kostyuk V. Y. (2008): Arc modeling in a plasmatron channel. IEEE Trans. Plasma Sci., No.1, Vol. 36, part 2, 293-298.

17. Serbin SI, Matveev IB, Goncharova MA (2014). Plasma Assisted Reforming of Natural Gas for GTL. Part I, IEEE Trans. Plasma Sci., vol. 42, no. 12, pp. 3896-3900

18. Matveev I., Matveeva S., Serbin S. (2007): Design and Preliminary Result of the Plasma Assisted Tornado Combustor. Collection of Technical Papers - 43rd AIAA/ ASME/SAE/ASEE Joint Propulsion Conference, Cincinnati, OH, AIAA 2007-5628, Vol. 6, 6091-6098.

19. Matveev I., Serbin S. (2012): Investigation of a reverse-vortex plasma assisted combustion system. Proc. of the ASME 2012 Heat Transfer Summer Conf., Puerto Rico, USA, HT201258037, 133-140.

20. Matveev I., Serbin S., (2006): Experimental and Numerical Definition of the Reverse Vortex Combustor Parameters. 44th AIAA Aerospace Sciences Meeting and Exhibit, Reno, Nevada, AIAA-2006-0551, 6662-6673.

21. Cherednichenko O., Serbin S. (2018): Analysis of Efficiency of the Ship Propulsion System with Thermochemical Recuperation of Waste Heat. J. Marine. Sci. Appl. No.1, Vol. 17, 122-130.

22. Serbin S.I. (2006): Features of liquid-fuel plasma-chemical gasification for diesel engines. IEEE Trans. Plasma Sci., 6, No.vol. 34, 2488-2496.

23. Serbin S.I. (1998): Modeling and Experimental Study of Operation Process in a Gas Turbine Combustor with a Plasma-Chemical Element. Combustion Science and Technology, Vol. 139, 137-158. 


\section{CONTACT WITH THE AUTHORS}

Oleksandr Cherednichenko

e-mail: cherednichenko.aleksandr65@gmail.com

Serhiy Serbin

e-mail:serbin1958@gmail.com

Admiral Makarov National University of Shipbuilding Heroyiv Ukraine av. 9

54025 Mykolaiv

UKRAINE

Marek Dzida

e-mail:dzida@pg.edu.pl

Gdańsk University of Technology

11/12 Gabriela Narutowicza Street

80-233 Gdańsk

Poland 